\title{
FOUR CASES OF DIABETES INSIPIDUS AND DISEASE
}

\author{
BY \\ JOHN D. SPILLANE \\ From the Department of Neurology and Neurosurgery, United Cardiff Hospitals
}

(RECEIVED FOR PUBLICATION OCTOBER 19, 1951)

The syndrome of diabetes insipidus may arise from many different lesions of the hypothalamohypophyseal mechanism. Destruction of the posterior lobe of the pituitary gland, the hypothalamo-hypophyseal tract, or the supra-optic nuclei bilaterally will produce the symptoms of polyuria and polydipsia, provided the anterior lobe of the pituitary gland remains functionally intact. It is a rare affection. In the majority of cases the pathological cause of the diabetes insipidus can be deduced during life, but there remains a small group of cases in which this is not possible.

This communication is concerned with the association of diabetes insipidus with diffuse pulmonary disease in four patients. The first patient was undoubtedly suffering from sarcoidosis in that he fell ill with fever, facial palsy, and uveoparotitis (Heerfordt), recovered, and later developed pulmonary disease and diabetes insipidus. The latter necessitated treatment with pitressin for 18 months. The second and third patients suffered from permanent diabetes insipidus and chronic -pulmonary "fibrosis" of obscure origin. The third patient showed progressive intellectual deterioration and his electroencephalogram was abnormal. In the fourth* patient diagnosis is not yet established, but sarcoidosis cannot be excluded.

\section{SARCoIdosis}

Case 1.-A man aged 35 years, an accountant, in August, 1946, when 31 years of age, developed an acute left facial palsy of peripheral type. It was at first considered that he was suffering from acute poliomyelitis, as his daughter had been taken ill with this disease three weeks earlier. However, no further paralysis developed and within two days there was painful bilateral swelling of the parotid and submaxillary glands. He ran a low fever for seven to 10 days and three weeks after the onset of his illness

\footnotetext{
- This patient came under my care after this paper had been written and is not discussed fully in relation to the literature. The case is, however, regarded as falling into one or other of the categories discussed.
}

developed bilateral acute iridocyclitis. Thereafter he $\underset{\oplus}{\vec{\omega}}$ made good progress except for one further episode of 0 iridocyclitis.

During 1947 his general condition improved, but $\vec{c}$ there was probably one mild recurrence of unilateral iridocyclitis. Early in 1948 he consulted his doctor $\mathbb{\Phi}$ because of shortness of breath, and was found to $\vec{\varphi}$ have bilateral enlargement of the hilar lymph nodes. N He was investigated at a nursing-home, but no further abnormalities were disclosed. He had no cough, and the little sputum obtained was negative for tubercle bacilli, even after culture and guinea-pig inoculation. The E.S.R. was $9 \mathrm{~mm}$. in one hour.

In July, 1948, he came under my observation. $\mathrm{He} \stackrel{\mathrm{Q}}{\mathbb{Q}}$ described how he had recently been troubled with $\stackrel{2}{\vec{P}}$ increasing thirst and polyuria. At first the polyuria was nocturnal and he would rise from his bed to urinate three or four times every night. This symptom was soon followed by excessive thirst. Investigation in hospital showed that he was suffering from true diabetes insipidus. Under controlled observation 음 he voided seven to 15 pints (4 to 8.5 litres) of urine $\stackrel{x}{x}$ daily and drank roughly equal amounts. The specific $\overline{0}$ gravity of the urine was usually in the neighbourhood of 1005 . He was pale, but not significantly anaemic (R.B.C. $4,275,000$ per c.mm.). On routine examination of the nervous system there was no abnormality. Power, tone, reflexes, and sensation were normal. The cerebrospinal fluid was normal. $\mathrm{He}$ was not $\frac{\mathrm{D}}{\mathrm{O}}$ noticeably short of breath, and the fingers were not clubbed. There was no enlargement of the lymphN nodes and the spleen could not be felt. The E.S.R. was $12 \mathrm{~mm}$. in one hour. A radiograph of the skull 0 was normal, but one of the chest revealed diffuse coarse fibrosis of both lungs with slight enlargement $O$ of the hilar lymph nodes (Fig. 1). Radiographs of the hands and feet were normal.

In July, 1948, he was first given an injection $(1 \mathrm{ml})$ 邑 of pitressin tannate in oil. It had an immediate and ${ }^{+}$ pronounced effect and for nearly 48 hours he was -0 relieved of his intolerable thirst. Subsequent observa- $\frac{}{\mathbb{D}}$ tion confirmed the diagnosis of diabetes insipidus and $\stackrel{\odot}{\circ}$ he developed no further symptoms. He left hospital $\stackrel{\odot}{\Omega}$ shortly afterwards and for the next three months was $\sigma$ content and happy when he was receiving $1 \mathrm{ml}$. of pitressin tannate in oil every other day. Repeated examination and radiographs of the limbs disclosed? 


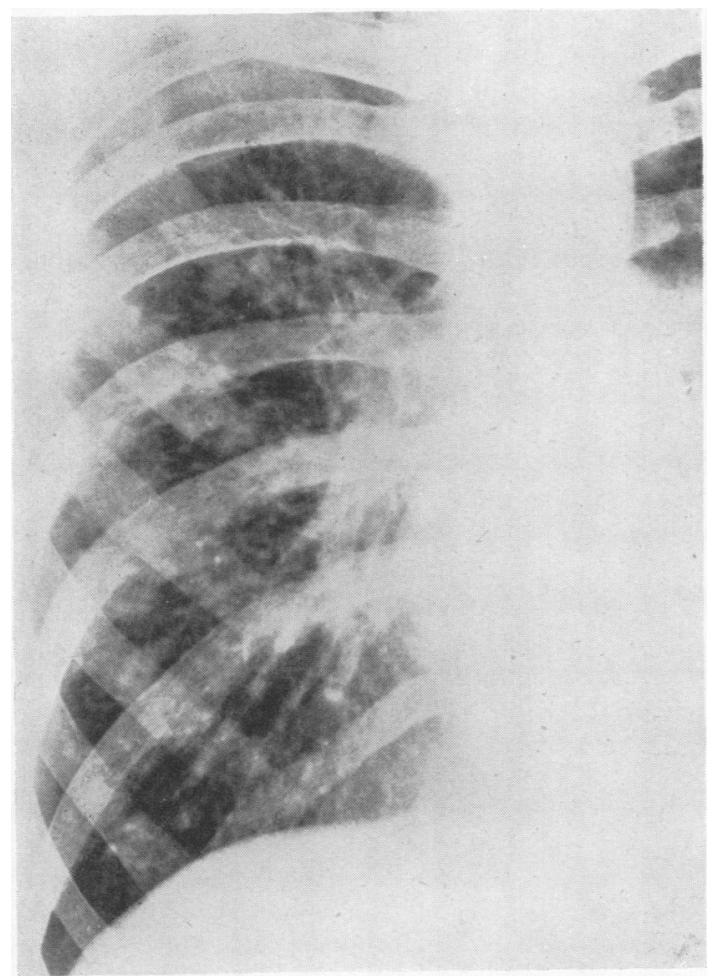

FiG. 1.-Coarse pulmonary reticulation in a case of Heerfordt's syndrome associated with diabetes insipidus (Case 1).

no further abnormalities and his general condition improved.

He was last seen in October, 1949, when his general condition had considerably improved and there had been further lessening of his thirst and polyuria.

In this case there was no previous history of pulmonary disease and the radiological discovery of enlargement of the hilar shadows was unexpected. Clinical examination of the chest at that time revealed no abnormality despite his complaint of shortness of breath. The latter is unusual in pulmonary sarcoidosis at that stage of the disease. Six months later there was little hilar node enlargement, but the lung markings were considerably accentuated and there was coarse mottling. There was never any evidence of tuberculosis, the sedimentation rate remained normal, and the Mantoux reaction negative to 1 in 200 O.T. At that time, 23 months after the original illness, he developed polyuria and polydipsia. He was a neurotic character and the possibility that his thirst was hysterical was entertained. Nevertheless, he did not merely excrete the excess of the water which he drank, and the first injection of pitressin gave dramatic relief for nearly 48 hours.
Kourilsky (1950) has questioned the view, long held by clinicians, that in diabetes insipidus thirst is a consequence of the dehydration resulting from polyuria. Careful clinical investigations suggest that there may be considerable dissociation between polydipsia and polyuria. In Kourilsky's cases the polydipsia fell into four groups : (1) pure polydipsia of hypothalamic origin ; (2) polydipsia resulting from partial destruction of the posterior lobe of the pituitary gland, when pitressin has a more or less definite action, and despite restriction of water intake there is no relative decrease in polyuria ; (3) polydipsia of pituitary origin remaining when the polyuria has stopped. Kourilsky points out that such cases were at first considered as psychogenic, but their organic nature he believes established. The persistence of thirst depended on the existence of conditioned reflexes. (4) Pure polydipsias which were completely uninfluenced by treatment with posterior pituitary extracts. In two cases examined at necropsy, of pulmonary tuberculosis and arteriosclerotic cerebral softening respectively, the supra-optic hypothalamic tract was normal. Kourilsky believes that because of the associated organic disorders it is a mistake to call these cases "psychogenic polydipsias." In my patient no effect followed the injection of normal saline.

Diabetes Insipidus in Sarcoidosis.-Case 1 is a typical example of that variety of sarcoidosis commonly known as uveoparotitis or Heerfordt's syndrome. In his original paper entitled "Febris Uveo-parotidea Subchronica " Heerfordt (1909) published an account of three cases, the last of which, a man of 25 years, developed polydipsia and polyuria (diuresis $5,000 \mathrm{ml}$. daily) with multiple cranial nerve palsies a month after the onset of parotitis.

At least 18 well-established instances of diabetes insipidus developing in patients with sarcoidosis have been reported (Table I). In a report on 300 cases of sarcoidosis Ricker and Clark (1949) made no mention of polydipsia and polyuria. Twentytwo cases came to necropsy and the pituitary was involved in one. Two patients died of Addison's disease. There are many further reports in which dryness of the mouth and thirst with or without frequent micturition are mentioned (Brewerton, 1910 ; Guillain, 1922 ; Jackson, 1925 ; Parker, 1926 ; Souter, 1929 ; Merrill and Oaks, 1931 ; Palmer, 1940). In cases without polyuria, of course, dryness of the mouth and excessive thirst are most likely to result from the bilateral involvement of the parotid and submaxillary glands. 


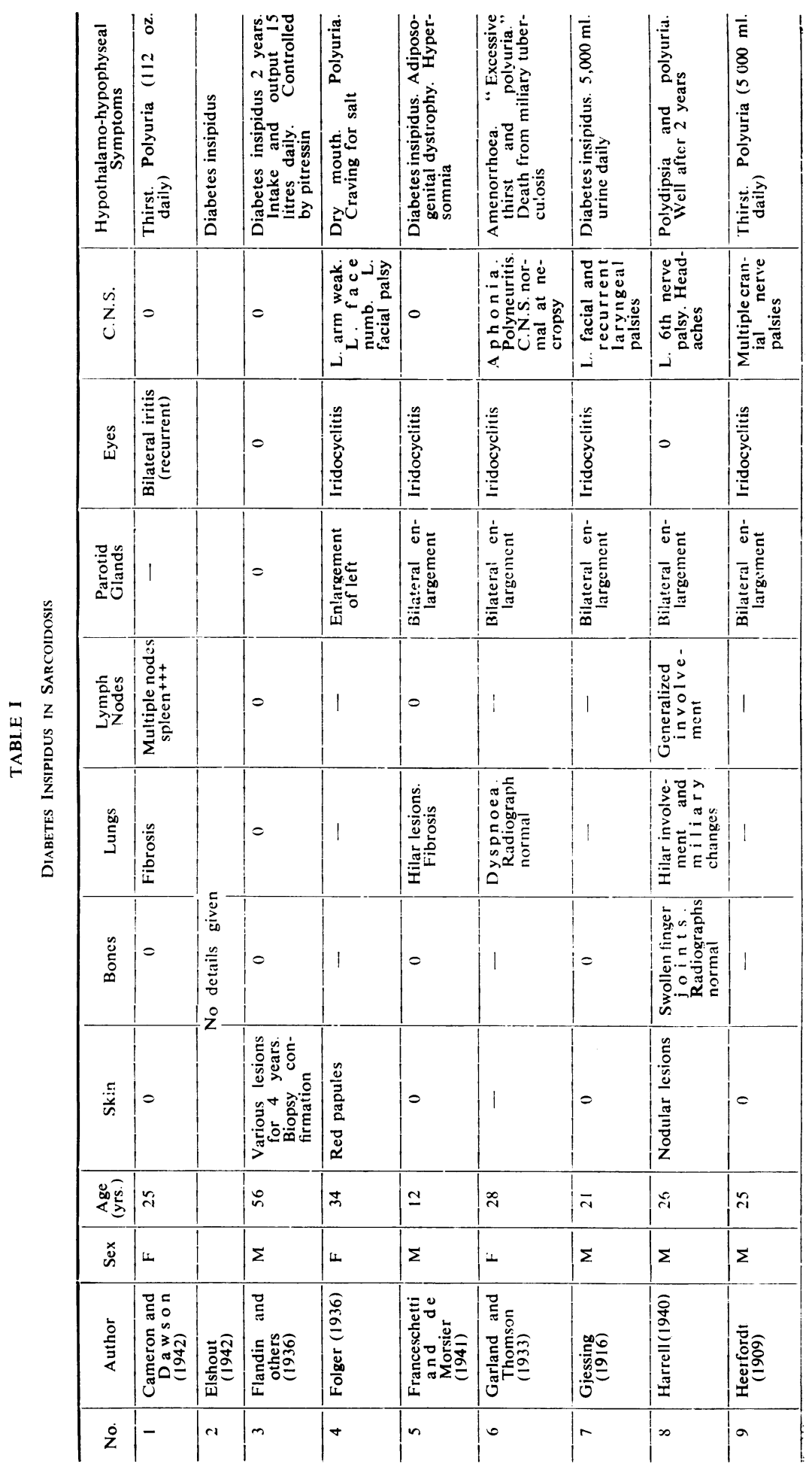




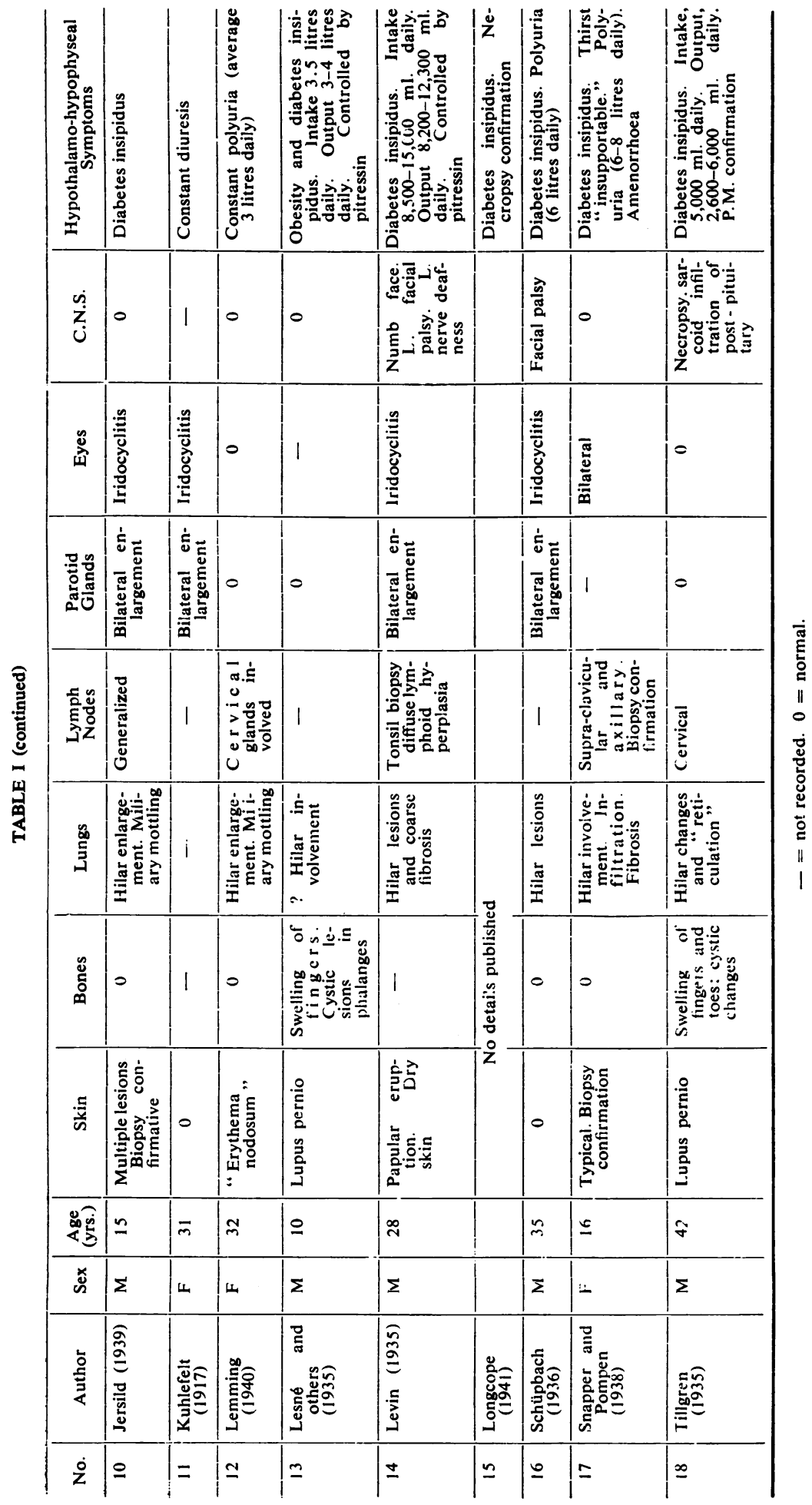

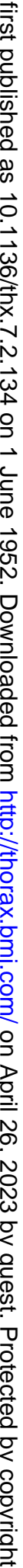


The many ways in which the nervous system can be affected in sarcoidosis have been examined by Colover (1948). He reviewed 115 cases from the literature and reported three further examples. The structures most likely to be affected are the optic nerves and retinae, the facial, glossopharyngeal, and vagus nerves, the pituitary gland, and the peripheral nerves. Meningoencephalitis and meningomyelitis occur in subacute and chronic forms and the brain and spinal cord may be infiltrated by sarcoid tissue or be affected by tumourlike masses in the dura mater. Hydrocephalus and adhesive arachnoiditis have been observed at operation. The cerebrospinal fluid may react by a pleocytosis and an increase in protein content.

In 12 of the 18 reported cases of sarcoidosis causing diabetes insipidus (Table $I$ ) the primary manifestation took the form of uveoparotid fever. In four cases (Nos. 3, 12, 13, and 18) there was no such syndrome and the sarcoid lesions involved, apart from the pituitary mechanism, only the skin, bones, and lungs. In Case 13 (Lesné, Launay, and Sée, 1935) lesions were present in the skin and phalanges; there was doubtful pulmonary involvement. In Case 18 (Tillgren, 1935) there was hilar node enlargement and pulmonary " reticulation" as well as characteristic lesions in the skin and phalanges. Case 3 (Flandin, Parat, and Paumeau-Delille, 1936) showed only characteristic cutaneous manifestations for two years before the appearance of polyuria. In Case 12 (Lemming, 1940) there was a history of erythema nodosum and cervical adenopathy in addition to pulmonary changes.

In these published cases, then, there were no examples of an association of pulmonary and pituitary disease only.

Other Hypothalamo-hypophyseal Syndromes in Sarcoidosis.-Reported cases of other hypo- thalamo-hypohyseal syndromes in sarcoidosis are $\stackrel{\overrightarrow{\vec{\omega}}}{\overrightarrow{0}}$ summarized in Table II.

In at least six recorded cases of sarcoidosis of the nervous system hypersomnia or lethargy was $\frac{\bar{\rho}}{\bar{\rho}}$ a feature (Colover, 1948). The distinction from $\mathbb{8}$ encephalitis lethargica in such cases is difficulto (Waldenström, 1937). Haas and Joseph (1908)reported iridocyclitis and parotitis in a boy show-ing infantilism; the patient described by Rogers $\vec{\omega}$ and Bodman (1926) developed narcolepsy Parker's case (1926) was observed to have loss of the pupillary accommodation reflex; Doub and $v$ Menagh (1929) described the case of a man aged! 30 years who showed the characteristic cutaneous $\vec{\perp}$ lesions of sarcoidosis, with swelling of the fingerso and typical radiological lesions in the metacarpals and phalanges, and developed a Fröhlich's syndrome with impotence, decreased sugar tolerance, and impaired mentality. In Toulant and Morard's. case (1936) Heerfordt's syndrome was associatede with retarded growth and infantile genitalia? Kraus (1942) described the case of a womano aged 41 years with polyuria, amenorrhoea, hypo-s trichosis, and genital dystrophy in whom ato necropsy there was sarcoid infiltration of the in $\frac{0}{2}$ fundibular area of the hypothalamus and the pituitary stalk and gland. Glass and Davis's (1944) patient was a man aged 54 years who became pro-3 gressively ill with weakness, anaemia, and failing vision. He became eunuchoid in appearance, withp testicular atrophy. There was acute infiltration of the hilar zone of the right lung and later of bothe lung fields. The course of the illness was febrilex and progressive. There was almost complete absence of steroid hormones in the urine, and. radiological examination of the skull showed earlyo intrasellar calcification. At necropsy the lungs and pituitary gland were seen to be invaded by $\$$ granulomatous process that was considered to

TABLE II

Other Hypothalamo-hypophyseal Syndromes in Sarcoidosis

\begin{tabular}{|c|c|c|c|c|c|}
\hline No. & Author & $\operatorname{Sex}$ & $\begin{array}{c}\text { Age } \\
\text { (yrs.) }\end{array}$ & Manifestations of Sarcoidosis & Hypothalamo-hypophyseal Disorders \\
\hline 1 & Toulant and Morard (1936) & $\mathbf{M}$ & 17 & Heerfordt's syndrome & Infantilism. Dysgenitalia \\
\hline 2 & Rogers and Bodman (1926) & $\mathbf{F}$ & 61 & Heerfordt's syndrome. Polyneuritis & Narcolepsy \\
\hline 3 & Haas and Joseph (1908) & $\mathbf{M}$ & 15 & Uveoparotitis & Infantilism \\
\hline 4 & Curtis and others (1947) & $\mathbf{M}$ & 25 & $\begin{array}{l}\text { Uveoparotitis. Bilateral facial palsy. Skin } \\
\text { lesion. Adenitis }\end{array}$ & Stupor (with papilloedema and aphasi \\
\hline 5 & Doub and Menagh (1929) & $\mathbf{M}$ & 30 & Skin lesion. Digits swollen. Cystic lesions & $\begin{array}{c}\begin{array}{c}\text { Fröhlich's syndrome. } \\
\text { tolerance }\end{array} \\
\end{array}$ \\
\hline 6 & Kraus (1942) & $\mathbf{F}$ & 41 & Miliary lung lesions. Anaemia. Wasting & $\begin{array}{l}\text { Amenorrhoea. Genital atrophy. Hyp } \\
\text { trichosis. Polyuria }\end{array}$ \\
\hline 7 & Glass and Davis (1944) & $\mathbf{M}$ & 54 & Pulmonary & $\begin{array}{l}\text { Eunuchism. Atrophic testes. Absence } \\
\text { urinary steroid hormones }\end{array}$ \\
\hline
\end{tabular}


be of sarcoid or tuberculous character. Curtis, Taylor, and Grekin (1947) reported the case of a man aged 25 years, with pulmonary and cutaneous sarcoid lesions, who became acutely ill with headache, fever, facial palsy, papilloedema, aphasia, and stupor. He survived, but there was permanent mental change. Sarcoid infiltration of the pituitary gland, its stalk, and the adjacent hypothalamic tissue has been observed at necropsy by Reis and Rothfeld (1931), by Schaumann (1941), by Longcope (1941), by Kraus (1942), and by Glass and Davis (1944).

\section{SARCoIDosis AND Tuberculosis}

Case 2.-In 1942 a man, then aged 28 years and serving in the R.A.F., reported sick with headaches. The details of this stage of his illness are not available, but it was discovered that his blood Wassermann reaction was positive. The C.S.F. was normal and its Wassermann reaction was negative. There was no history of acquired syphilis and two brothers also proved to have positive Wassermann reactions. For several years he received routine courses of antisyphilitic treatment and his headaches rapidly subsided. He left the R.A.F. in 1946 in category A1

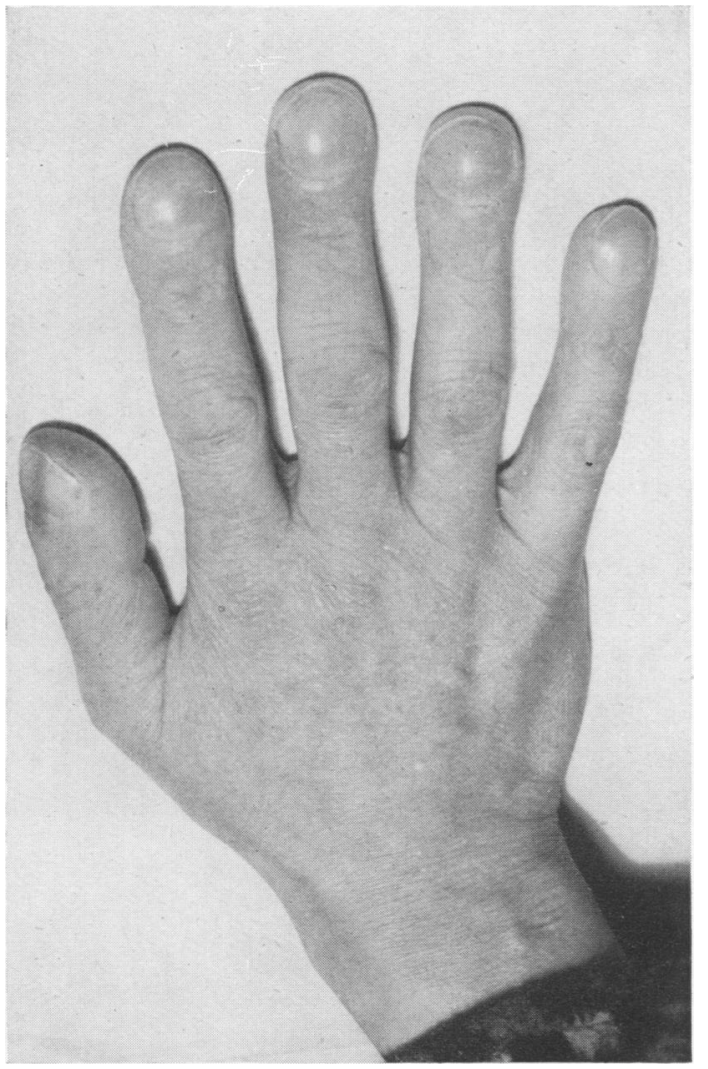

Fig. 2.-Clubbing of fingers in Case 2. after 10 years' service. About one year later he tried to re-enlist, but he was rejected because a routine radiological examination disclosed "pulmonary fibrosis." The sputum was negative, the Mantoux reaction was negative to 1 in 100 O.T., and the E.S.R. was $20 \mathrm{~mm}$. in one hour.

Soon afterwards he first became aware of shortness of breath on exertion. He had no cough, there was no haemoptysis, but occasionally he had sharp stabbing pains in the right side of the chest. He remained in much the same condition until early in 1947, when he began to be troubled with excessive thirst and the passing of large amounts of urine. He lost about $28 \mathrm{lb}$. (13 kg.) in weight in a year, and before receiving pitressin injections he passed large quantities of pale urine every half-hour by day and night. $\mathrm{He}$ was first admitted to hospital in 1948 and later came under my observation. His general condition was poor and he had lost strength. He was pale, with a moderate hypochromic anaemia ( $\mathrm{Hb} 80 \%$ ). He was not dyspnoeic at rest, but rapidly became so on mounting stairs. There was considerable clubbing of the fingers (Fig. 2) and toes, but no cyanosis. The cardiovascular system was normal. Chest expansion was $2 \frac{1}{2}$ in. Clinical examination of the lungs revealed no abnormality. Radiography showed diffuse bilateral miliary mottling without enlargement of the hilar lymph nodes (Fig. 3). There was scanty sputum, and tests for tubercle bacilli were repeatedly negative. He was intelligent and co-operative and showed no evidence of intellectual or personality changes. There was blunting of pinprick sensation over the right side of the face and forehead, with a reduced corneal reflex; the pupils were slightly unequal but reacted normally. The optic discs and visual fields were normal. The blood Wassermann reaction was negative, and the cerebrospinal fluid was normal. Radiographs of the skull, hands, and feet were normal, and an air encephalogram showed a normal ventricular system with no excess of air over the cortex. The only abnormality of the skin, apart from dryness, consisted of areas of fat atrophy on the outer aspects of both thighs where he was accustomed to administer pitressin injections. Without treatment he voided 10 to 20 pints (5.7 to 11.4 litres) of urine daily. The effect of $1 \mathrm{ml}$. of pitressin tannate in oil lasted 18 to 24 hours. Plasma globulins were normal. The blood cholesterol level was $235 \mathrm{mg}$. per $100 \mathrm{ml}$. Intravenous pyelography was normal. The Mantoux reaction was positive to 1 in 1,000 O.T. Sarcoidosis had been diagnosed before he was referred to me.

Calciferol $(150,000$ units daily) by mouth for three months exerted no influence on his lesions. The dyspnoea was more marked and at times he was cyanosed. There had been no evidence of spontaneous pneumothorax, and it was considered inadvisable to induce pneumothorax artificially as in Case 3. The honeycomb appearance of the lungs on the radiograph was not as marked as in Case 3, and tomograms did not assist in deciding whether there were cystic changes in the lungs. Lateral radiographs 


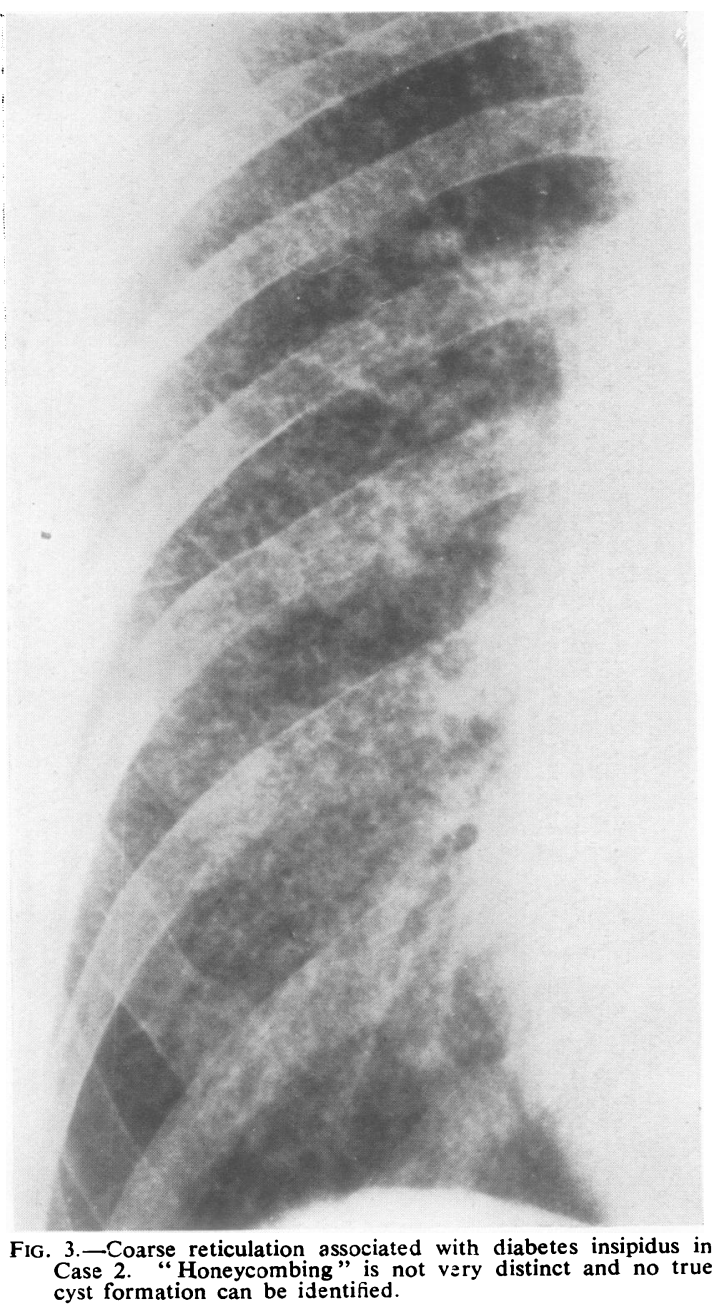

did not reveal cystic spaces beneath the sternum. Careful radiography of the skeleton revealed no abnormality.

This patient suffered from congenital syphilis. His blood Wassermann reaction was found to be positive when he was 28 years of age. The C.S.F. was then normal and chest radiographs during that period had excited no comment. At the age of 32 he was found to have diffuse pulmonary fibrosis and soon afterwards he became short of breath on exertion and the fingers became clubbed. In his thirty-fourth year he developed diabetes insipidus. The latter has now been present for nearly three years and remains unaltered in severity. It is controlled by pitressin.

The only abnormalities disclosed on examination of the nervous system were slight pupillary inequality and loss of sensation of the right cornea and over the right side of the face and forehead. $\stackrel{\vec{F}}{\stackrel{\vec{S}}{+}}$ The cerebrospinal fluid was normal.

The question that naturally arose was whether흘 the diabetes insipidus, the pulmonary fibrosis, or both, were syphilitic in origin. In rejecting this explanation the following points were borne in mind. First, the patient's syphilis was undoubtedly $\vec{O}$ congenital and only discovered on routine inves- tigation for headaches in his twenty-ninth year. $\vec{\omega}$ The nervous system and the cerebrospinal fluid? were then normal. Secondly, by the time thex pituitary disorder developed, the blood Wassermann reaction had become negative. The cerebro-spinal fluid remained normal. Thirdly, the late ${ }_{+}^{\omega}$ development of unilateral involvement of the fiftho cranial nerve can hardly be attributed to syphilis in these circumstances.

It is difficult to imagine that such uncommon and separate manifestations of congenital syphilis would make their appearance during the thirde decade in this manner. Much more likely is if that both pulmonary and pituitary symptoms areo a manifestation of another disease. The pos sibilities will be considered in the discussion that follows the description of Case 3 .

Case 3.- In 1944 a man, then aged 30 years and serving in the Army in East Africa, began to suffero from excessive thirst. On his admission to hospita? it was estimated that fluid intake varied between seven and 14 pints (four to eight litres) and urinary output. between eight and 20 pints (4.5 to 11.4 litres) daily (specific gravity of the urine 1000-1010). He passed urine every two hours during the day and usuallyx three times at night. Apart from the evidence of los of weight he appeared to be well, but a radiograpl? of the chest showed diffuse, fine miliary infiltration of the lungs. There was no enlargement of the hilas lymph nodes. No Mantoux test was possible at this stage, but six examinations of sputum were negative for tubercle bacilli. The E.S.R. was $9 \mathrm{~mm}$. in on hour. The skin was normal. Radiographs of the skull and of the hands and feet disclosed no abnor 0 mality. The blood urea level was $24 \mathrm{mg}$. per $100 \mathrm{mt}^{\circ}$ A blood urea clearance test showed $118 \%$ of normab renal function in the first hour and $62 \%$ in the second hour (mean $90 \%$ ).

He was invalided home with a diagnosis of diabetes insipidus and was discharged from the Army in 1945 In May, 1945, round, scaly erythematous lesions, some? of them nodular, appeared on the skin of the hands right thigh, and abdomen. They varied in size from a threepenny piece to a shilling. The Mantoux tes屯্ was negative to 1 in 100 O.T. The E.S.R. at thi\& time was $9 \mathrm{~mm}$. in one hour. He was then firs troubled by shortness of breath on exertion and there were occasional asthmatic attacks and bouts of rhinorrhoea. Biopsy and histological examination of one of the skin nodules showed "zones of round-cell infiltra 
tion in the deep layers of the cutis with macrophages, endothelial cells, lymphocytes, and plasma cells." An intramuscular injection of $1 \mathrm{ml}$. of pitressin controlled the polyuria for 24 to 48 hours.

In January, 1947, he developed a small, left-sided pneumothorax. At this time the radiographic changes in the lungs had progressed, but there was no evidence of hilar enlargement and the appearances were those of extensive fine miliary mottling with fibrosis. The Wassermann reaction was negative, the C.S.F. normal. Sputum examinations were negative for tubercle and the Mantoux test $(1: 1,000$ O.T.) was still negative : higher concentrations were not used.

He came under my observation in May, 1949. He was now noticeably inefficient at his work. His memory for recent and remote events was poor, speech was at times slurred and indistinct, and his aptitude for figures was very much below that of the average bank clerk. He was frequently anxious and irritable, and yet at other times would laugh foolishly and show lack of insight. Radiography of the chest revealed diffuse coarse reticulation (Figs. 4 and 5).

In July, 1950, the Mantoux test (1:1,000 O.T.) was positive. He produced no sputum. No changes had developed in the bones of the hands or feet. The blood cholesterol level was $283 \mathrm{mg}$. per $100 \mathrm{ml}$.; the blood Wassermann reaction was negative. There was no evidence of cutaneous xanthomatosis. In January, 1951, there was a further small left-sided pneumo-

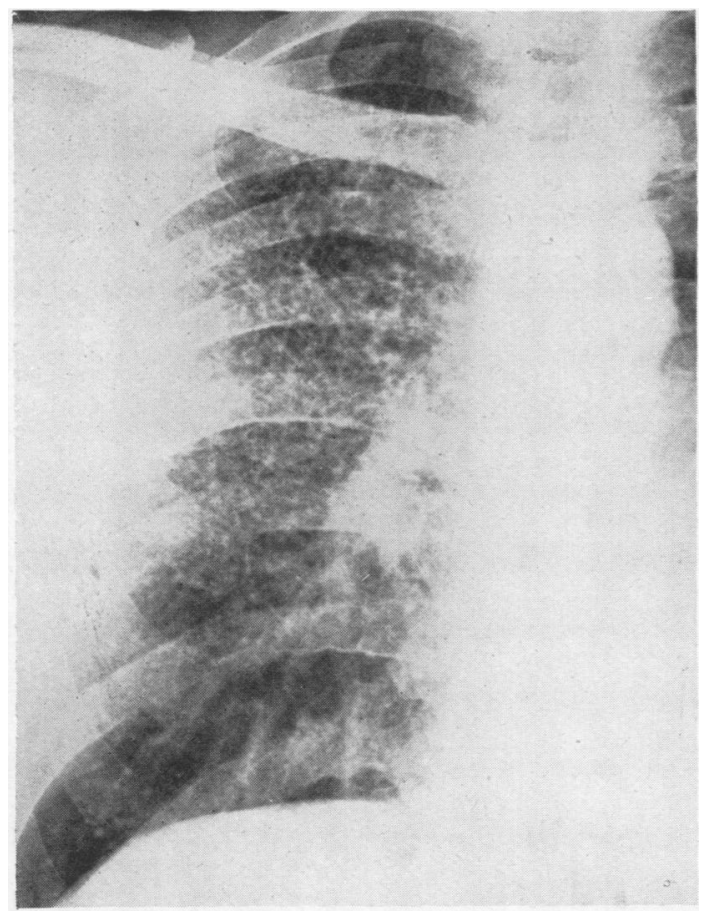

FIG. 4.-Coarse reticulation associated with diabetes insipidus in Case 3. The "honeycomb" appearance is more apparent than in Case 2. In this case biopsy of a cutaneous nodule a few years in Case 2 . In this case biopsy of a cutaneous nodule a few years
previously was said to have disclosed the changes of sarcoidosis.

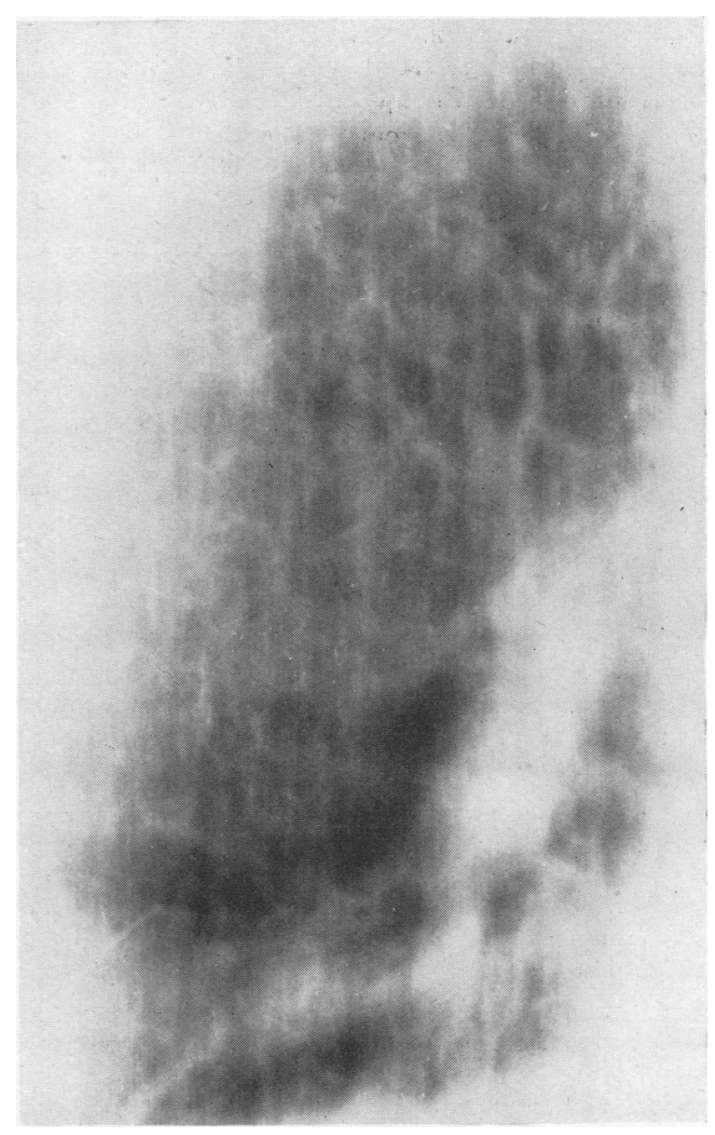

FIG. 5.-Tomogram of Case 3 showing the " honeycomb" effect.

thorax. This absorbed and chest expansion and air entry remained good. He still experiences considerable dyspnoea on effort, and occasionally adventitious sounds are heard in both lung bases.

His wife described how his personality had deteriorated. He was now facile and rather child-like in his attitude to his illness. At times he was pleasant and co-operative, but sometimes there were bouts of temper or anxiety or depression. He was not disorientated and there were no hallucinations or delusions. Tests of intellectual function revealed a fairly gross deficit. Speech was slow, monotonous, and at times slurred. There were no narcoleptic attacks, but he was generally somnolent by day. There were no significant abnormalities on routine examination of the nervous system. Lumbar puncture revealed a normal cerebrospinal fluid pressure $(120 \mathrm{~mm}$.) with a free rise and fall on jugular compression; protein content of the cerebrospinal fluid was $50 \mathrm{mg}$. per $100 \mathrm{ml}$.; the Wassermann reaction was negative. A lumbar air encephalogram showed that the ventricular system was normal and there was no excess of air over the hemispheres. An electroencephalogram showed considerable abnormality; there was a clearly defined moderate potential theta 
rhythm with a predominant frequency of $6 \frac{1}{2}$ cycles per sec.; slower waves in the theta band were also present. This activity appeared bilaterally in all leads, the amplitude in the frontal leads being lowest. Low potential delta waves appeared as little more than a base-line sway, also bilaterally. There was no alpha rhythm in the record.

Intravenous pyelography and urinary concentration and dilution tests were normal. The third urinary specimen of the concentration test showed a specific gravity of 1030 . There was a mild normocytic anaemia $(4,120,000$ R.B.C. per c.mm.). The plasma globulins were normal.

Calciferol by mouth $(150,000$ units daily) was prescribed. This dosage was reached gradually and without side-effects.

In May, 1951, an artificial pneumothorax was induced on the right side, but the honeycomb appearance of the compressed lung was not much enhanced. At that time the film illustrating a pneumothorax he had experienced a few months previously was not available to me (Fig. 6). It shows, however, some accentuation of the honeycomb appearance of the compressed left lung.

Fig. 6.-Spontaneous pneumothorax on the left side enhances the "honeycomb" appearance of the compressed lung in Case 3 .
No abnormality has been discovered in the skeleto $\overrightarrow{\vec{\pi}}$ on careful radiological examination.

In neither Case 2 nor Case 3 can a diagnosis \&્f sarcoidosis be established. In Case 2 there was no tissue available for biopsy (liver puncture wars not performed). In Case 3 sarcoidosis was cons sidered to be the interpretation of the histological changes observed in a skin nodule several yea $\overrightarrow{8}$ previously, but the specimen has not been available to me. In neither case have any cutaneous lesiow developed during my period of observation. There was no adenopathy or enlargement of liver or. spleen. There were no cystic lesions in the boness Serum proteins were normal. None of thes factors, however, can be taken to exclude the possibility of sarcoidosis, and the literature, as already stated, contains many examples of diabetęs insipidus occurring in sarcoidosis.

Writing of pulmonary sarcoidosis, Scadding (1950) described several different radiologicad appearances : (1) enlargement of hilar lymph nod@s without detectable lung changes; (2) bilaterit enlarged lymph nodes with diffuse mottling in the lungs; (3) diffuse pulmonary infiltration witho it gross evidence of hilar lymph node enlargementa; (4) fine reticulation ; (5) fibrosis, emphysema, an bulla formation. Scadding continues :

"Correlating my own experience with reports in the literature, I think the earliest intrathoracic lesion of sarcoidosis is usually hilar lymph-node enlargemen which may be shortly followed or more rareß accompanied by a more or less diffuse pulmonar infiltration varying from a fine micro-nodular type resembling miliary tuberculosis to coarser irregulä mottling. Possibly some cases start with the pulmo nary infiltration without a preceding stage of hilif lymph-node enlargement. Infiltrations of either type may either clear completely so far as radiograph\& appearances are concerned, or persist for a variable time with a variable amount of replacement by fibrosis. This fibrosis most frequently takes the form of irregular coarse strands, usually in the middte zones, with gross emphysematous changes elsewhere or it may more rarely be of much finer type giving rise to a fine reticulated appearance in the radiograph This latter appearance may easily be missed on inspe tion of the radiograph; it is accompanied, howeven by a considerable diminution in the patient's vit capacity and correspondingly severe functional difability. In the cases which present the picture of fibrosis and emphysema tubercle bacilli may event $\&$ ally appear in the sputum, although the radiograph appearances may not show any immediate correspon $\frac{{ }_{0}}{f}$ ing change."

The good general condition, the insensitivity tuberculin, and the clinical course of the affection are points that indicate that the pulmonary proces in any given case is more likely to be sarcofo than tuberculous. "But it must be admitted states Scadding, "that the differentiation between chronic miliary tuberculosis and sarcoidosis is 
many instances little more than a verbal one." It will be remembered that the Mantoux reaction was considered to have been negative in the early stages of the disease in Cases 2 and 3 of this report, but in each case it was positive when the patient came under my care. The ultimate development of tuberculosis is, of course, frequent in sarcoidosis, but it is very improbable that the early invasion of the thalamo-pituitary region was tuberculous. Diabetes insipidus occasionally develops as a terminal event in tuberculosis, and it is known that bronchogenic carcinoma can present with the syndrome of diabetes insipidus (Peabody and Olsen, 1951).

Examination of the literature concerning diabetes insipidus in sarcoidosis has not disclosed any case in which the lesions were confined to the pituitary region and the lungs. Clubbing of the fingers, which was observed in Case 2 , is an uncommon finding in pulmonary sarcoidosis which has progressed to fibrosis. In Case 3, the progressive mental deterioration and the advance of the cerebral lesion with apparent quiescence of the pulmonary disturbance are difficult to reconcile with a diagnosis of sarcoidosis. The radiological appearance of the lungs in Case 2 has not altered during the past four years.

It is therefore considered that sarcoidosis is not the likely explanation of the syndrome in these two cases.

Case 4.-A 32-year-old carpenter was admitted to hospital in January, 1952, because of loss of weight, dyspnoea on exertion, and excessive thirst with polyuria. He was well until two years previously, and had never worked in a dusty atmosphere. In February, 1950, he developed a perianal abscess which required drainage. The chest was not radiographed at the time. He recovered and remained well until a year ago, since when he had lost $28 \mathrm{lb}$. (13 kg.) in weight. His appetite deteriorated and he became short of breath on exertion. In October, 1951, he was referred to a chest clinic, and radiography showed pneumonic consolidation in the right mid-zone. He was febrile, and was sent home to bed under the care of his own doctor. A second radiograph taken a month later showed that the area of consolidation had resolved.

When admitted to hospital two months later he was sallow and his skin was rather dry. He had recently been troubled with excessive thirst. At night he would retire to bed with two jugfuls of water, and during the 24 hours he estimated that he drank about 12 pints of water in addition to fluids taken at mealtimes. There was increasing polyuria. He remained alert, cheerful, had no difficulty in concentrating, and his memory remained good. His sleep rhythm was unchanged, and there was no somnolence by day.

His eyes were prominent, but he said they had always been so (confirmed by photographs). The tip of the spleen could be felt, and a few small lymph nodes were palpable in the axillae. The fingers were not clubbed. Chest expansion was less than 1 in., but there were no adventitious sounds. Neurological examination revealed no abnormality: C.S.F., normal ; E.E.G., normal. The specific gravity of the urine was 1005 to 1008 , and there was no glycosuria. The average daily intake of fluids was 10 to 12 pints. The glucose tolerance curve was normal, the fasting blood sugar $80 \mathrm{mg}$. per $100 \mathrm{ml}$. The blood cholesterol level was $208 \mathrm{mg}$., the serum albumin $3.4 \mathrm{~g}$., and globulin 1.9 g. per $100 \mathrm{ml}$.; albumin-globulin ratio $1.8: 1.0$. The blood Wassermann reaction was negative. The E.S.R. was $33 \mathrm{~mm}$. in one hour. Thymol turbidity was 3 units. Leucocytes were 5,000 per c.mm. (neutrophils $60 \%$, lymphocytes $26 \%$, monocytes $13 \%$, eosinophils $1 \%$ ). Haemoglobin was $96 \%$. The Mantoux test was positive ( 1 in 100 O.T.). No tubercle bacilli were found in the sputum.

Radiography of the skull and skeleton gave normal results, and of the chest (Fig. 7) fine pin-head mottling evenly distributed throughout both lung fields; no cysts were detected, the hilar shadow was normal, and there was no pneumothorax. Tomography disclosed no further lesions.

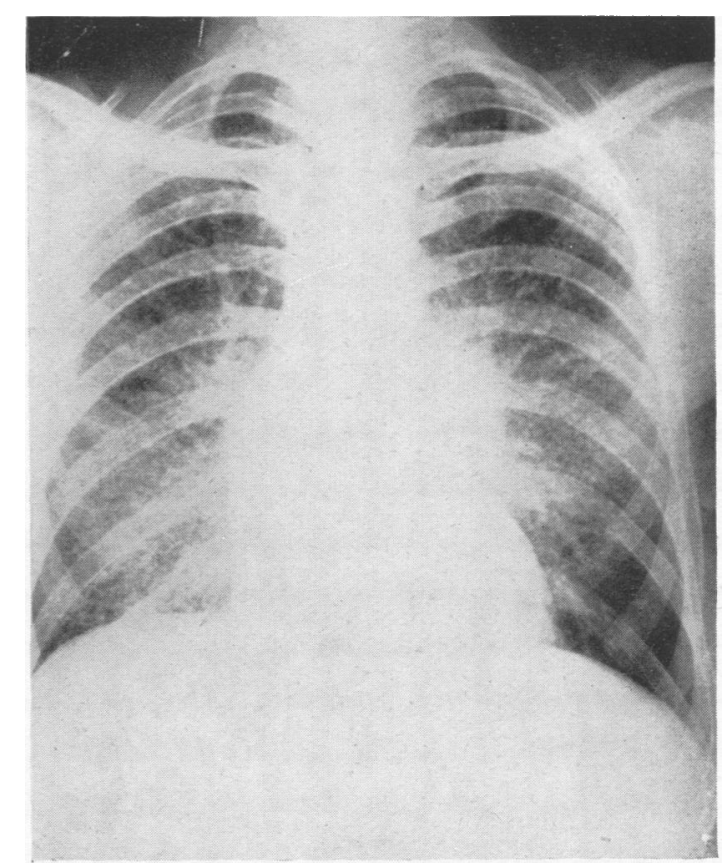

FIG. 7.-Fine pin-head mottling in both lung fields in Case 4.

The sternal marrow was normal, with no excess of eosinophils (Dr. Roger Seale).

The patient's general condition is good. Pitressin tannate, $1 \mathrm{ml}$. in oil, given intramuscularly, controls the thirst and polyuria for about 36 hours. Diagnosis is not established. The patient would not permit biopsy of an axillary lymph node. Sarcoidosis cannot be excluded, and inability to demonstrate pulmonary cystic changes does not of course exclude a granulo- 
matous or xanthomatous process in the lungs. The case is regarded as falling into one or other of the categories discussed in this paper.

\section{" Honeycomb Lungs" aND Diabetes Insipidus}

Oswald and Parkinson (1949) have drawn attention to what they have termed " honeycomb lungs." The condition is characterized by " thin-walled cysts distributed uniformly throughout the substance of both lungs, varying in size up to a maximum of $1 \mathrm{~cm}$. in diameter." They have collected 16 such cases. In six the pulmonary lesions formed part of a general medical disorder. In the other 10 cases the disease seemed to be solely pulmonary. They believed that their cases represented " a single variety of cystic disease" of the lungs. Distinctive clinical features included spontaneous pneumothorax, frequently bilateral, and progressive right heart failure which was almost invariably the cause of death. They pointed out that xanthomatosis, tuberous sclerosis, biliary cirrhosis, and pituitary disorders have been reported in association with the radiological picture of "honeycomb lungs." The latter, they concluded, occurs in a variety of diseases in which there is diffuse interstitial pulmonary infiltration, but the radiological appearances are remarkably constant. "Throughout both lung fields a reticular pattern is seen, varying from fine to coarse." The् honeycomb appearance was accentuated by colo lapse of the lung during pneumothorax, and in four cases was clearly demonstrated by tomo graphy. The authors pointed out that similar but not identical, appearances may be caused b pneumoconiosis, lymphangitis, carcinomatosis? and chronic miliary tuberculosis. In a persona $\Phi$ communication Oswald (1951) states that sarcoid $\overrightarrow{\overrightarrow{1}}$ osis does not give rise to "honeycomb lungs." Histological studies of " honeycomb lungs" were్ made by Cunningham and Parkinson (1950). ㄴ

What is particularly interesting about these cases of "honeycomb lungs" is the occasiona association with pituitary disorder. One of theis patients (Case 5) was a pituitary dwarf; no abnormality was found in the central nervous system. Another patient (Case 6) had diabete insipidus. He was 36 years of age and had had diabetes insipidus for nine years. There had beeff one spontaneous pneumothorax and the fingers were clubbed. In this case, on different occasions? enlarged cervical lymph nodes, palpable liver an spleen, and a soft mass behind the left sterno $\bar{\partial}$ mastoid were noted. Radiography of the lung showed a coarse reticulation and mottling through out. No biopsy was performed and he died with $\overrightarrow{\bar{\sigma}}$

TABLE III

“ Honeycomb Lungs" Associated with Pituitary Disorders

\begin{tabular}{|c|c|c|c|c|c|c|c|c|}
\hline Authors & Sex & $\begin{array}{c}\text { Age } \\
\text { (yrs ) }\end{array}$ & $\begin{array}{c}\text { Spon- } \\
\text { taneous } \\
\text { Pneumo- } \\
\text { thorax }\end{array}$ & $\begin{array}{c}\text { Right } \\
\text { Heart } \\
\text { Failure }\end{array}$ & $\begin{array}{c}\text { Pulmonary } \\
\text { Reticu- } \\
\text { lation }\end{array}$ & $\begin{array}{c}\text { Bone } \\
\text { Erosions }\end{array}$ & $\begin{array}{l}\text { Pituitary } \\
\text { Disorders }\end{array}$ & $\begin{array}{l}\text { Miscellaneous } \\
\text { Observations }\end{array}$ \\
\hline $\begin{array}{l}\text { Weidman and Free } \\
\text { man (1924) }\end{array}$ & $\mathbf{M}$ & 9 & $-^{*}$ & - & - & Skull & $\begin{array}{l}\text { Diabetes insipidus } \\
\text { Ravenous ap- } \\
\text { petite }\end{array}$ & $\begin{array}{l}\text { Necropsy, cystic lungs and } \\
\text { xanthomatosis. }\end{array}$ \\
\hline $\begin{array}{c}\text { Oechsii and Miles } \\
(1934)\end{array}$ & $\mathbf{M}$ & 22 & ++ & $\begin{array}{l}\text { Cause of } \\
\text { death }\end{array}$ & + & - & $\begin{array}{l}\text { Diabetes insipidus } \\
\text { Fröhlich's syn- } \\
\text { drome }\end{array}$ & No details of necropsy \\
\hline $\begin{array}{l}\text { Berg and Zachrisson } \\
(1941)\end{array}$ & $\mathbf{M}$ & 30 & ++ & Nil & + & - & Diabetes insipidus & \\
\hline Ackermann (1944) & $\mathbf{F}$ & 25 & + & Nil & + & $\begin{array}{l}\text { Peivis and } \\
\text { long bones }\end{array}$ & Diabetes insipidus & \\
\hline $\begin{array}{l}\text { Oswald and Parkin- } \\
\text { son (1949) (Case 5) } \\
\end{array}$ & $\mathbf{M}$ & 15 & + & + & + & Nil & Pituitary dwarf & \\
\hline $\begin{array}{r}\begin{array}{c}\text { Oswald and Parkin- } \\
\text { son (1949) (Case 6) }\end{array} \\
\end{array}$ & $\mathbf{M}$ & 38 & + & + & + & - & Diabetes insipidus & \\
\hline $\begin{array}{l}\text { Oswald and Parkin- } \\
\text { son (1949) (Case 8) }\end{array}$ & $\mathbf{M}$ & 12 & +++ & Nil & Nil & - & $\begin{array}{l}\text { Diabetes insipidus } \\
\text { (temporary) }\end{array}$ & $\begin{array}{l}\text { Necropsy, } \\
\text { Brain and pystic lun } \begin{array}{c}\text { pituitary ngt } \\
\text { examined }\end{array}\end{array}$ \\
\hline $\begin{array}{l}\text { Lewis and Smart } \\
(1951)\end{array}$ & $\mathbf{M}$ & 21 & Nil & Nil & + & Nil & Diabetes insipidus & \\
\hline Spillane (Case 2) & $\mathbf{M}$ & 36 & Nil & Nil & + & Nil & Diabetes insipidus & $\begin{array}{l}\text { Mantoux reaction chang } \\
\text { from negative to positive } \frac{\rho}{\Phi}\end{array}$ \\
\hline Spillane (Case 3) & $\mathbf{M}$ & 36 & ++ & Nil & + & Nil & Diabetes insipidus & $\begin{array}{l}\text { Progressive dementia Abnom } \\
\text { mal E.E.G. Mantoy } \\
\text { reaction changed from negł } \\
\text { tive to positive }\end{array}$ \\
\hline
\end{tabular}


out further information coming to light. Another of Oswald and Parkinson's patients (Case 8), a boy of 12 years, complained of polyuria. His daily urinary output varied from four to six litres (S.G 1001). Treatment with pituitrin improved the polyuria (full details not available). Cystic lungs were found at necropsy. Oswald and Parkinson found reports of three cases in the literature in which diabetes insipidus was associated with "honeycomb lungs," one patient, in addition, suffering from Fröhlich's syndrome (Oechsli and Miles, 1934 ; Berg and Zachrisson, 1941; Ackermann, 1944). The first of these cases came to necropsy and the lungs showed a diffuse honeycomb structure with interstitial fibrosis. Histologically the pituitary was said to "resemble parathyroid tissue," but no details were given. The patient, a man aged 22 years, had several episodes of pneumothorax and death resulted from congestive heart failure with cyanosis. The authors were undecided about the aetiology of the pulmonary cystic condition. They noted an absence of inflammatory reactions in the lungs and raised the question of the congenital origin of the cysts.

\section{Xanthomatosis}

It is well known that diabetes insipidus may result from xanthomatous changes in the pituitary gland as in Hand-Schüller-Christian disease. Pulmonary xanthomatosis is not so widely recognized. The radiological signs of "honeycomb lungs" have been observed in xanthomatosis with and without evidence of pituitary, skeletal, and cutaneous involvement. The pulmonary changes may result from diffuse infiltration with lipoid material or from widespread interstitial fibrosis and cyst formation (Oswald and Parkinson, 1949). Writing of the lipoidoses, Thannhauser (1950) describes a case of diabetes insipidus in which there were disseminated xanthomatous lesions of the skin without cranial or pulmonary involvement. The blood cholesterol was normal. He does not mention diabetes insipidus in cases of generalized xanthomatosis of the normocholesterolaemic type, but stressed the radiological similarity of the pulmonary disease to that of miliary tuberculosis.

Lewis and Smart (1951) state that Weidman and Freeman (1924), in reporting the necropsy of a case described by Griffith (1922), were the first to describe cystic lung changes with diabetes insipidus. The case was that of a boy of 9 years who had jaundice, xanthomatous lesions of the skin and the skull, and diabetes insipidus. The blood cholesterol was $397 \mathrm{mg}$. per $100 \mathrm{ml}$. At necropsy the posterior pituitary was fibrotic and xanthic; there was a small interpeduncular xanthic tumour.
The lungs were said to cut like a rubber sponge and showed large alveoli, emphysematous bullae, fibrosis, and patches of xanthic deposit. Oswald and Parkinson referred to Griffith's paper but not to the necropsy. Lewis and Smart reported the case of a man, aged 21 years, with diabetes insipidus, "honeycomb lungs," and a normal blood cholesterol. They believe that such cases come into the category of normocholesterolaemic xanthomatosis as classified by Thannhauser.

In Cases 2 and 3 of this report no xanthomatous lesions of the skin were observed. Extensive radiological investigation revealed no abnormalities of the skeleton. In Case 2 the blood cholesterol was $235 \mathrm{mg}$. per $100 \mathrm{ml}$. and in Case 3 it was $283 \mathrm{mg}$. per $100 \mathrm{ml}$. The latter figure is high.

\section{Tuberous ScLEROSIS}

"Honeycomb lungs" in tuberous sclerosis was first described by Berg and Vejlens (1939), but diffuse cyst-like changes in the lungs with infiltration by fibrous and myomatous tissue was described by von Stoessel (1937). In two patients with progressive dyspnoea and cyanosis (one with pneumothorax), with enlargement of the hilar shadows and a miliary radiological appearance, von Stoessel found at necropsy lung surfaces like " hob-nailed livers." He considered that there was a diffuse pulmonary "muscular cirrhosis."

Diabetes insipidus was not present in any of the cases of tuberous sclerosis since described in which there were signs, radiological or pathological or both, of diffuse " myomatosis" of the lungs (Berg and Zachrisson, 1941; de Fine Licht, 1942 ; Rosendal, 1942 ; Samuelsen, 1942 ; Paliard, Plauchu, Galy, and Papillon, 1946; Berg and Nordenskjöld, 1946 ; Oswald and Parkinson, 1949). Adenoma sebaceum, epilepsy, subungual fibromata, phakomata, and bony changes are inconstant in these case reports.

Berg and Zachrisson (1941) described three cases of cystic lung changes in tuberous sclerosis. The first two came to necropsy and the characteristic lesions of tuberous sclerosis were found in various organs. But the third case, a man of 30 years, also had diabetes insipidus with a history of a spontaneous pneumothorax. He was still alive and well and the radiological appearances of the lungs resembled miliary tuberculosis and cystic disease. There were no other abnormalities. The possibilities of sarcoidosis and xanthomatosis were not considered. There was certainly no proof of tuberous sclerosis, which was the presumptive diagnosis.

Ackermann (1944) also considered his case to be one of tuberous sclerosis. A man, aged 25 years, 
had diabetes insipidus for two years. He developed chest trouble and entered a tuberculosis sanatorium. Radiography of the chest revealed an "irregular honeycomb pattern" and he later had a spontaneous pneumothorax. Lipoid metabolism was normal. The skull was normal. However, there were multiple cystic changes in the pelvis and long bones, which may occur in tuberous sclerosis (Sutton and Liversedge, 1951), so that a diagnosis of normocholesterolaemic xanthomatosis, excluded by Ackermann, was not really justified.

The diagnostic difficulties encountered in " honeycomb lungs" are well illustrated by the case reported, with necropsy, by Samuelsen (1942). A man, aged 49 years, was for several years in a tuberculosis sanatorium, believed to be suffering from miliary tuberculosis. Cystic lesions developed in the phalanges and were revealed by radiography. The diagnosis was then altered to one of sarcoidosis, but after death typical lesions of tuberous sclerosis were discovered in the brain and kidneys. The lungs showed diffuse fibrosis and nodular interstitial thickening with accumulation of pigment.

Rosendal's (1942) patient with "honeycomb lungs" was thought to be suffering from pulmonary tuberculosis or sarcoidosis, but at necropsy there was diffuse pulmonary myomatosis and cystic dilatation of alveoli and bronchioles. The final diagnosis was in doubt. In this case, as in that of de Fine Licht (1942), there were no other changes at necropsy, but both authors noted the resemblance to the pulmonary pathology in cases of proved tuberous sclerosis.

As far as I know diabetes insipidus has not been described in tuberous sclerosis.

\section{SUMmary}

Four cases are described in which there was an association of diabetes insipidus and diffuse pulmonary disease.

The first case was one of sarcoidosis, a disease in which diabetes insipidus and other hypothalamohypophyseal syndromes occur from time to time. Following a characteristic uveoparotitis with facial palsy, the patient developed hilar lymphnode enlargement and later coarse pulmonary fibrosis and diabetes insipidus.

In the second and third cases diabetes insipidus was associated with diffuse pulmonary disease which caused a fine reticular pattern, of the " honeycomb" type, on the radiograph. It was more evident in Case 3 in which pneumothorax, artificial and induced, enhanced the " honeycomb" appearance of the pulmonary radiograph. In addition, in Case 3, there was mental deterioration.
In neither case were there any bony lesions on radiological examination. The blood cholesterof levels were 235 and $283 \mathrm{mg}$. per $100 \mathrm{ml}$. respec tively. It is suggested that these two cases are examples of xanthomatosis affecting the lungs an $\mathbb{R}^{2}$ the pituitary region, and the differential diagnosis from sarcoidosis is discussed. In the fourth cas 5 no cystic changes have been demonstrated in the lungs. The Mantoux reaction is positive.

The general question of the aetiology of cases of diabetes insipidus (and other hypothalamox hypophyseal syndromes) associated with " honeycomb "lungs is considered in the light of these case reports and of similar ones in the literature Necropsy studies will be necessary to confirm the true nature of such cases, but they are presumably examples of disordered lipoid metabolism.

I am indebted to Dr. Arthur M. Jones for his hel 1 ⿸尸 in the interpretation of the radiographs and for his kind co-operation. Dr. H. A. Evans responded to myer request to induce a pneumothorax in Case 3 , and $\mathrm{P}$ am very grateful. Dr. A. J. Thomas kindly referre Case 4 to me. Mr. H. A. Griffiths, of the Departs ment of Clinical Photography, Llandough HospitaP Penarth, provided the clinical photographs and preg pared the illustrations.

\section{REFERENCES}

Ackermann, A. J. (1944). Amer. J. Roentgenol., 51, 315.

Berg, G. and Nordenskjöld, A. (1946). Acta med. scand. 125, 428 Berg, G., and Vejlens, G. (1939). Acta paediatr. (Stockh.), 26, 16. - and Zachrisson, C. G. (1941). Acta radiol. (Stockh.), 22, 425 Brewerton, E. W. (1910). Trans. ophthal. Soc. U.K., 30, 148.

Cameron, C., and Dawson, E. K. (1942). Edinb. nied. J., 49, 737 Colover, J. (1948). Brain, 71, 451.

Cunningham, G. J., and Parkinson, T. (1950). Thorax, 5, 43

Curtis, A. C., Taylor, H., and Grekin, R. H. (1947). J. invest. Derm $\times$ $9,131$.

Doub, H. P., and Menagh, F. R. (1929). Amer. J. Roentgenol., 2 P 149.

Elshout, C. (1942). Ned. Tijdschr. Geneesk., 86, 1473.

Fine Licht, E. de (1942). Acta radiol. (Stockh.), 23, 151.

Fitz, R. (1914). Arch. intern. Med., 14, 706.

Flandin, C., Parat, M., and Paumeau-Delille, G. (1936). Bull. So巳 méd. Hop. Paris, s2, 1423.

Folger, H. P. (1936). Arch. Ophthal. (Chicago), 15, 1098.

Franceschetti, A., and de Morsier, G. (1941). Rev. méd. Suisse rom $61,129$.

Garland, H. G., and Thomson, J. G. (1933). Quart. J. Med., n.s., \& 157.

Gjessing, H. G. A. (1916). Klin. Mbl. Augenheilk., 56, 252

Glass, S. J., and Davis, S. (1944). J. clin. Endocrinol., 4, 489.

Griffith, J. P. C. (1922). Arch. Pediat., 39, 297.

Guillain, G. (1922). Bull. Acad. Méd. (Paris), es, 80.

Haas, G., and Joseph, H. (1908). Ann. Oculist (Paris), 130, 130.

Harrell, G. T. (1940). Arch. intern. Med., 65, 1003.

Heerfordt, C. F. (1909). v. Graefes Arch. Ophthal., 70, 254.

Jackson, B. H. (1925). Amer. J. Ophthal., 8, 361 .

Jersild, M. (1939). Ar.n. Derm. Syph. (Paris), 7 ser., 10, 641.

Kourilsky, R. (1950). Proc. roy. Soc. Med., 43, 842.

Kraus, E. J. (1942). J. Lab. clin. Med., $28,140$.

Kuhlefelt, E. (1917). Brit. J. Ophthal., 1, 621.

Lemming, R. (1940). Actu med. scand., 103, 400. Lemming, R. (1940). Actu med. scand., 103, Launay, C., and Sée, G. (1935). Bull. Soc. méd. Hóô
Paris, 81, 1137.

Levin, P. M. (1935). J. nerv. mert. Dis., 81, 176.

Lewis, A. A. G., and Smart, J. (1951). Proc. roy. Soc. Med. (Sect Endocrin.), 44, 166.

Longcope, W. T. (1941). J. Amer. med. Ass., 117, 1321.

Merrill, H. G., and Oaks, L. W. (1931). Amer. J. Ofhthal., 14, 
Oechsli, W. R., and Miles, S. H. (1934). Amer. Rev. Tuberc., $30,239$. Oswald, N. (1951). Personal communication.

- and Parkinson, T. (1949). Quart. J. Med., 18, 1.

Paliard, Plauchu, Galy, P., and Papillon (1946). Poumon, 2, 205.

Palmer, J. H. (1940). Canad. med. Ass. J., 43, 11.

Parker, G. (1926). Bristol med.-chir. J., 43, 73.

Peabody, H. D., and Olsen, A. M. (1951). Proc. Mayo Clin., 26, 107.

Rabinowitch, I. M. (1921). Arch. intern. Med., 28, 355.

Reis, W., and Rothfeld, J. (1931). v. Graefes Arch. Ophthal., 126, 357.

Ricker, W., and Clark, M. (1949). Amer. J. clin. Path., 19, 725.

Rogers, B., and Bodman, J. H. (1926). Bristol mad.-chir. J., 43, 84.

Rosendal, T. (1942). Acta Radiol. (Stockh.), 23, 138.

Rowntree, L. G. (1921). Med. Clin. N. Amer., 5, 439.

- (1924). J. Amer. med. Ass., 83, 399.

Samuelsen, E. (1942). Acta Radiol. (Stockh.), 23, 373

Scadding, J. G. (1950). Brit. med. J., 1, 745.

Schaumann, J. (1941). Acta n.ed. scand., 106, 239.

Schüpbach, A. (1936). Schweiz. med. Wschr., 17, 1182.

Snapper, I., and Pompen, A. W. M. (1938). Pseudo-tuberculosis in Man. Haarlem, p. 23.

Souter, W. C. (1929). Trans. ophthal. Soc. U.K., $49,113$.

Stoessel, E. von (1937). Beitr. Klin. Tuberk., 90, 432.

Sutton, D., and Liversedge, L. A. (1951). J. Facult. Radiol. (Lond.), $2,224$.

Thannhauser, S. J. (1950). Lipidoses. New York, Lnd ed., p. 370

Tillgren, J. (1935). Brit. J. Derm., 47, 223.

Toulant, P., and Morard, G. (1936). Arch Ophtal., 53, 321

Waldenström, J. (1937). Acta med. scand., 91, 53.

Weidman. F. D., and Freeman, W. (1924). Arch. Derm. Syph. (Chicago), 9, 149.

\section{A D D E N D U M}

Since this paper was submitted for publication Case 3 has died. The relevant post-mortem changes were as follows (Dr. W. Jones Williams) :

Axillary and pubic hair was sparse.

There was moderate atheroma of the coronary vessels and aorta, and an ante-mortem thrombus in the aorta at the origin of the left testicular artery.

Both lungs were cystic. Cysts were numerous, up to $2 \mathrm{~cm}$. in diameter, giving a honeycombed appearance (Fig. 8). There was bronchopneumonia in the lower lobes. Microscopically between the cysts interstitial fibrosis and eosinophils were seen. The mediastinal gland showed lymph stasis and numerous eosinophils.

The left kidney showed numerous small cortical infarcts.

The testis was small, and histology showed atrophy of the tubules with no mature sperms and with an increase of fibrous tissue.

Yellowish flecks were seen in the hypothalamus. The pituitary gland and stalk and frontal lobes were macroscopically and microscopically normal. Histology of the hypothalamus showed replacement by "granulomatous" tissue, consisting of islands of " endothelioid" cells, perivascular lymphocytic cuffing, and numerous eosinophils.

The sella turcica appeared normal macroscopically, but the histology showed an increased number of eosinophils. A similar picture was found in the sternal marrow. Fat stains of the various organs showed no increase in the lipoid content.

The changes in the hypothalamus were considered to be indicative of an eosinophilic type of granuloma of unknown cause but similar to those previously described. The picture in some areas was reminiscent of sarcoidosis.

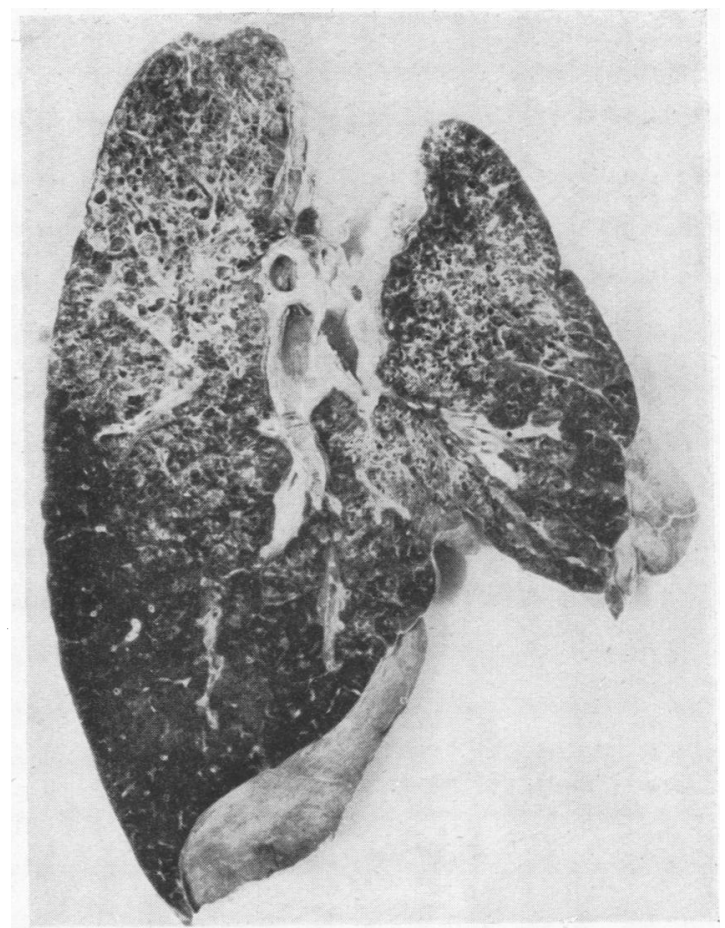

Fig. 8.-Cut surface of lung in Case 3, showing cystic changes.

The lung changes appear compatible with the healing stage of an eosinophilic granuloma.

There were no features found in any organ to suggest the syndrome of Hand-Schüller-Christian or Letterer Siwe, which are regarded as related to eosinophilic granuloma.

Also since this paper was written Dennis and Rosahn (1951) have reported the case of a man of 30 years of age who died after an illness of two years and eight months' duration with diabetes insipidus and cystic lungs. He had much pain in the chest and at least one attack of spontaneous pneumothorax. At necropsy the lungs were cystic and the pituitary gland and hypothalamus were invaded by many mononuclear cells, histiocytes, lymphocytes, some eosinophils and, in the hypothalamus, occasional giant and plasma cells. The case was not diagnosed before death, and the authors concluded that it represented a granulomatous disease involving the reticulo-endothelial system. One of the cases of diabetes insipidus reported by Cates and Garrod (1951) was of a patient who was suffering from xanthomatosis and honeycomb lungs and also developed an eosinophil granuloma of bone.

\section{REFERENCES}

Cates, J. E., and Garrod, O. (1951). Clin. Sci., 10, 145. Dennis, J. W., and Rosahn, P. D. (1951). Amer. J. Path., 27, 627. 